\title{
Hydration with Mannitol and Dextrose May Promote Cisplatin-Induced Nephrotoxicity: Test of Five Protocols of Hydration during Cisplatin Therapy in Rat Models
}

\author{
Mohammad-Sedigh Khosravi, ${ }^{1}$ Alireza Samimiat, ${ }^{1}$ Bahar Mazaheri, ${ }^{1}$ Farzaneh Ashrafi, ${ }^{1,2}$ \\ Ardeshir Talebi, ${ }^{1,3}$ and Mehdi Nematbakhsh $\oplus^{1,4,5}$ \\ ${ }^{1}$ Water \& Electrolytes Research Center, Isfahan University of Medical Sciences, Isfahan, Iran \\ ${ }^{2}$ Department of Internal Medicine, Oncology-Hematology Section, Isfahan University of Medical Sciences, Isfahan, Iran \\ ${ }^{3}$ Department of Clinical Pathology, Isfahan University of Medical Sciences, Isfahan, Iran \\ ${ }^{4}$ Department of Physiology, Isfahan University of Medical Sciences, Isfahan, Iran \\ ${ }^{5}$ Isfahan ${ }^{M N}$ Institute of Basic \& Applied Sciences Research, Isfahan, Iran \\ Correspondence should be addressed to Mehdi Nematbakhsh; nematbakhsh@med.mui.ac.ir
}

Received 25 March 2021; Revised 1 July 2021; Accepted 20 September 2021; Published 4 October 2021

Academic Editor: Mahmoud Elsabahy

Copyright (c) 2021 Mohammad-Sedigh Khosravi et al. This is an open access article distributed under the Creative Commons Attribution License, which permits unrestricted use, distribution, and reproduction in any medium, provided the original work is properly cited.

\begin{abstract}
Backgrounds. Cisplatin (CP) still is a novel choice for solid tumor therapy, but it is accompanied with the side effect of nephrotoxicity. Hydration may reduce the risk of CP-induced nephrotoxicity, while the issue is still challenging. In this study, five types of hydration protocols including saline, mannitol, dextrose saline, saline plus furosemide, and saline plus mannitol were examined in both sexes of rats during CP therapy. Methods. Seventy-six male and female Wistar rats in 14 groups of experiments were subjected to CP therapy, and five types of hydration protocols were implemented, and the induced nephrotoxicity was evaluated via biochemical markers, kidney function parameters, and pathology investigation. Results. Male and female rats had different responses to hydration protocol types. The higher mortality rate was seen in female rats that received mannitol or dextrose hydration types. In addition, the serum levels of blood urea nitrogen (BUN) and creatinine (Cr) and sodium excretion fraction $(\mathrm{ENa} \%)$ increased and the clearance of $\mathrm{Cr}(\mathrm{ClCr})$ decreased significantly $(P<0.05)$ in female rats hydrated with saline plus furosemide or mannitol plus saline-treated groups. The worsened condition in male rats is observed in the mannitol hydration group with a significant decrease of $\mathrm{ClCr}$ and significant increase of serum $\mathrm{BUN}$ and $\mathrm{Cr}$ and $\mathrm{ENa} \%(P<0.05)$. The higher kidney tissue damage score (KTDS) in the mentioned groups verified the findings. Conclusion. Hydration with mannitol or dextrose promotes the risk of nephrotoxicity during CP therapy with more intensity on the female.
\end{abstract}

\section{Introduction}

Nowadays, cisplatin (CP) is recognized as a choice treatment for a wide range of solid tumors in clinic. In spite of its great effect on improvement of survival, it causes many complications such as nephrotoxicity. The renal manifestations of $\mathrm{CP}$ therapy may accompany with acute and chronic renal failure, tubular acidosis, or renal salt wasting [1]. Nephrotoxicity has still remained as the most common and important usage limiter of CP [2]. The kidney eliminates CP, while the main site of injury is in the renal epithelial cells of proximal tubule where the $\mathrm{CP}$ concentration increases to three times the serum concentration. Therefore, the nuclear and mitochondrial DNA injury and cells death (apoptosis) were performed, and furthermore, the reactive oxygen species generation and inflammatory mechanisms are also related in the CP-induced nephrotoxicity process $[1,3-5]$. In addition, there are some risk factors for $\mathrm{CP}$-induced nephrotoxicity including sex, history of renal dysfunction, drug dose, and the frequency of drug administration, older 
age, female gender, and hypoalbuminemia $[1,5,6]$, while diabetes and organic cation transporter 2 (OCT2) polymorphisms are considered as decreased risks factors for CPinduced nephrotoxicity [1]. However, in the animal model, it was found that $\mathrm{CP}$ therapy promotes the induced nephrotoxicity in male more than female [6].

Several studies have been done in order to assess the protective effect of different synthetic and herbal antioxidants supplements against $\mathrm{CP}$-induced nephrotoxicity [7-11]. In addition, other studies have been tried to alleviate the adverse effect of CP-induced nephropathy [12-14]. However, hydration and diuretics also devote to protect the kidney against CP-induced nephrotoxicity $[15,16]$. By hydration with or without diuretic, the renal excretion is increased, and the contact duration of drug with the renal tubules is decreased, and the risk of CP-induced nephrotoxicity may attenuate, but the issue is still challenging. In this current study, five types of hydration protocols including saline, mannitol, dextrose saline, saline plus furosemide, and saline plus mannitol were examined in both sexes of rats during CP therapy, and the induced nephrotoxicity was evaluated.

\section{Methods}

2.1. Animals. Seventy-six female and male $(209 \pm 1.7 \mathrm{~g})$ Wistar rats (Animal Center, Isfahan University of Medical Sciences, Isfahan, Iran) were used in this study. Animals were housed in the controlled conditions (12/12 light/dark cycles; $23-25^{\circ} \mathrm{C}$ ). This study approved by Isfahan University of Medical Sciences Ethics Committee (IR.MUI.MED.REC.1399.707 for male rats and IR.MUI.MED.REC.1399.708 for female rats).

2.2. Experimental Design. The animals were divided randomly into 14 groups of experiments (groups 1-7 and groups 8-14 included male and female rats, respectively).

\subsubsection{Experimental Groups}

(1) Groups 1 (male, $n=6$ ) and 8 (female, $n=6$ ) are named NS $+\mathrm{CP}+\mathrm{NS}$. The animals in these groups initially received normal saline (NS, $15 \mathrm{ml} / \mathrm{kg}$, ip), and 1 hour later, CP $(7.5 \mathrm{mg} / \mathrm{kg}$, ip) was administrated. Then, after 1 hour post-CP injection, the second injection of NS $(15 \mathrm{ml} / \mathrm{kg}$, ip) was done.

(2) Groups 2 (male, $n=6$ ) and 9 (female, $n=6$ ) are named $\mathrm{M}+\mathrm{CP}+\mathrm{M}$, and groups 3 (male, $n=6$ ) and 10 (female, $n=6$ ) are named DS $+\mathrm{CP}+\mathrm{DS}$. The animals in these groups had the same regimen of group 1 , but the $\mathrm{M}+\mathrm{CP}+\mathrm{M}$ groups received mannitol (M, $15 \mathrm{ml} / \mathrm{kg}$, ip) and the DS + CP + DS received dextrose saline (DS, $15 \mathrm{ml} / \mathrm{kg}$, ip) instead of NS.

(3) Groups 4 (male, $n=6$ ) and 11 (female, $n=6$ ) are named NS $+\mathrm{CP}+\mathrm{NS}, \mathrm{F}$. The rats initially received NS $(15 \mathrm{ml} / \mathrm{kg}$, ip), and 1 hour later, CP $(7.5 \mathrm{mg} / \mathrm{kg}$, ip) was administrated. Then, after 1 hour post-CP injection, the combination of NS $(12.5 \mathrm{ml} \mathrm{kg}$, ip $)$ and furosemide $(\mathrm{F}, 2.5 \mathrm{ml} / \mathrm{kg}$, ip) was administrated.

(4) Groups 5 (male, $n=6$ ) and 12 (female, $n=6$ ) are named $\mathrm{M}, \mathrm{NS}+\mathrm{CP}+\mathrm{NS}$. The animals of these groups initially received combination of NS $(7.5 \mathrm{ml} /$ $\mathrm{kg}$, ip) and $\mathrm{M}(7.5 \mathrm{ml} / \mathrm{kg}$, ip), and 1 hour later, $\mathrm{CP}$ $(7.5 \mathrm{mg} / \mathrm{kg}, \mathrm{p})$ was injected. Then, after 1 hour post$\mathrm{CP}$ injection, the NS $(15 \mathrm{ml} / \mathrm{kg}$, ip) was administrated.

(5) Groups 6 (male, $n=6$ ) and 13 (female, $n=6$ ) are named CP. The rats in these groups received $\mathrm{CP}$ $(7.5 \mathrm{mg} / \mathrm{kg}$, ip) alone without any hydration.

(6) Groups 7 (male, $n=4$ ) and 14 (female, $n=4$ ) are named NS. These rats had the regimen-like group 6 or 13 , but they received $\mathrm{NS}(0.5 \mathrm{ml} / \mathrm{kg}$, ip) instead of $\mathrm{CP}$.

2.2.2. Measurements. The animals were observed for period of 7 days, but before the end of experiment, they are kept in standard metabolic cages for 6 hours to collect urine. Finally, the blood samples were obtained by heart puncture under anesthesia, and the animals were sacrificed humanly. The kidneys were excised and weighted immediately to obtain the kidney weight (KW). The left kidney was used for histopathology investigations via hematoxylin and eosin (H\&E) staining. Based on existence of vacuolization, dilatation, hyaline cast, debris, or degeneration, the renal damage was assigned as the kidney tissue damage score (KTDS), and it was scored from 1 to 4 , while zero score was recorded for normal tissue $[17,18]$. The right kidney was homogenized in specific volume of saline and centrifuged, and the supernatant was used for assessment of the kidney level of nitrite and malondialdehyde (MDA). The serum levels of creatinine $(\mathrm{Cr})$, blood urea nitrogen $(\mathrm{BUN})$, nitrite, $\mathrm{MDA}$, and the $\mathrm{Cr}$ concentration in urine were measured. The serum level of nitrite was determined by the Griess method [19]. The urine and plasma sodium $(\mathrm{Na})$ concentrations were also measured. The $\mathrm{Cr}$ clearance $(\mathrm{ClCr})$, urine flow rate (UF), and the percentage of excretion $\mathrm{Na}$ fraction $(\mathrm{ENa} \%)$ were also determined.

2.3. Statistical Analysis. Data are expressed as mean\pm standard error of the mean. The levels of BUN, Cr, MDA, nitrite, $\mathrm{UF}, \mathrm{ClCr}, \mathrm{ENa} \%, \mathrm{KW}$, and bodyweight (BW) change were compared between each two groups using the $t$-Student test. Comparison of the KTDS between the groups was assessed using the Mann-Whitney test. $P<0.05$ was considered as significant.

\section{Results}

3.1. Animal Survival. The survival time (in days) for each group of male and female rats is given in Table 1. In general, male groups have more survival time rather than female groups. The groups of $\mathrm{M}+\mathrm{CP}+\mathrm{M}$ and $\mathrm{DS}+\mathrm{CP}+\mathrm{DS}$ that have the highest number of deaths in female sex showed a significant difference when compared with NS and CP 


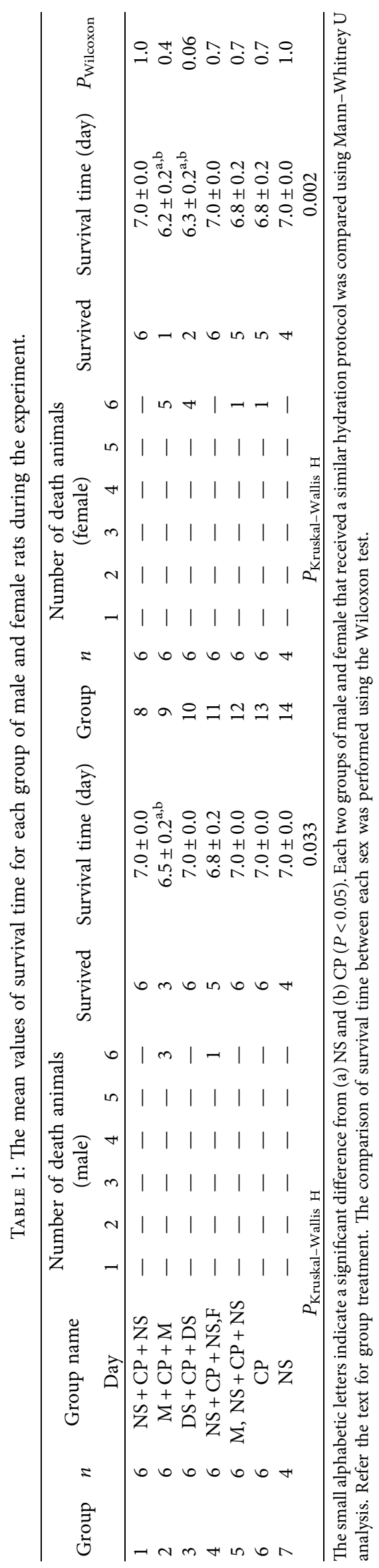


TABLE 2: The effect of cisplatin (CP).

\begin{tabular}{|c|c|c|c|c|c|c|}
\hline \multirow{2}{*}{ Parameter/group } & \multicolumn{3}{|c|}{ Male } & \multicolumn{3}{|c|}{ Female } \\
\hline & NS & $\mathrm{CP}$ & $P$ & NS & $\mathrm{CP}$ & $P$ \\
\hline BUN (mg/dl) & $24.0 \pm 0.4$ & $128.4 \pm 42.6$ & 0.06 & $21.2 \pm 1.2$ & $146.0 \pm 49.2$ & 0.04 \\
\hline $\mathrm{Cr}(\mathrm{mg} / \mathrm{dl})$ & $0.4 \pm 0.0$ & $1.4 \pm 0.4$ & 0.09 & $0.57 \pm 0.0$ & $1.5 \pm 0.4$ & 0.05 \\
\hline KW (g/100 g BW) & $0.7 \pm 0.1$ & $1.3 \pm 0.0$ & 0.01 & $0.6 \pm 0.0$ & $1.0 \pm 0.0$ & $<0.0001$ \\
\hline $\mathrm{BW}(\%$ change $)$ & $3.8 \pm 2.0$ & $-23.3 \pm 2.5$ & $<0.0001$ & $11.5 \pm 1.1$ & $-22.8 \pm 1.7$ & $<0.0001$ \\
\hline KTDS & $0.5 \pm 0.2$ & $3.5 \pm 0.2$ & 0.02 & $0.2 \pm 0.2$ & $3.4 \pm 0.6$ & 0.01 \\
\hline $\mathrm{UF}(\mu \mathrm{l} / \mathrm{min} \mathrm{g} \mathrm{kW})$ & $5.5 \pm 2.1$ & $6.0 \pm 1.1$ & 0.85 & $6.9 \pm 2.0$ & $8.8 \pm 1.8$ & 0.52 \\
\hline $\mathrm{ClCr}(\mu \mathrm{l} / \mathrm{min} \mathrm{g} \mathrm{kW})$ & $530.1 \pm 153.0$ & $109.5 \pm 34.0$ & 0.03 & $334.5 \pm 69.2$ & $125.9 \pm 28.0$ & 0.03 \\
\hline $\mathrm{ENa}(\%)$ & $1.0 \pm 0.2$ & $2.6 \pm 1.3$ & 0.29 & $0.91 \pm 0.24$ & $1.0 \pm 0.3$ & 0.78 \\
\hline SNitrite $(\mu \mathrm{mol} / \mathrm{L})$ & $10.52 \pm 1.2$ & $13.37 \pm 3.6$ & 0.52 & $10.28 \pm 1.4$ & $24.58 \pm 3.7$ & 0.01 \\
\hline $\operatorname{SMDA}(\mu \mathrm{mol} / \mathrm{L})$ & $4.9 \pm 0.1$ & $3.2 \pm 0.2$ & $<0.0001$ & $3.8 \pm 0.24$ & $4.1 \pm 0.15$ & 0.35 \\
\hline KNitrite $(\mu \mathrm{mol} / \mathrm{g}$ tissue $)$ & $182.6 \pm 4.2$ & $148.0 \pm 9.0$ & 0.01 & $187.6 \pm 19.7$ & $103 \pm 7.0$ & $<0.0001$ \\
\hline KMDA (nmol/g tissue) & $64.2 \pm 2.7$ & $29.1 \pm 1.2$ & $<0.0001$ & $65.9 \pm 4.1$ & $58.1 \pm 11.8$ & 0.55 \\
\hline
\end{tabular}

$P$ values are obtained by the $t$-Student test. BUN, blood urea nitrogen; $\mathrm{Cr}$, creatinine; KW, kidney weight; BW, bodyweight; KTDS, kidney tissue damage score; UF, urine flow rate; $\mathrm{ClCr}$, clearance of $\mathrm{Cr}$, ENa\%, excretion fraction of sodium; SMDA and KMDA, serum and kidney levels of malondialdehyde; serum and kidney levels of nitrite in normal saline (NS) and CP-treated groups of male and female rats.

groups. Furthermore, in male rats, there is the highest number of death in the $\mathrm{M}+\mathrm{CP}+\mathrm{M}$ group with survival time of $6.5 \pm 0.2$ days.

3.2. The Data for the Higher Mortality Rate Groups. According to survival time table (Table 1), the number of survived female rats in groups $9(\mathrm{M}+\mathrm{CP}+\mathrm{M})$ and 10 $(\mathrm{DS}+\mathrm{CP}+\mathrm{DS})$ which were hydrated with mannitol and dextrose, respectively, were less than 3 animals which are not enough to analyze. However, the data for BUN, Cr, KW, percentage change of bodyweight (\% BW), and KTDS in one animal survived in group $9(\mathrm{M}+\mathrm{CP}+\mathrm{M})$ were $553 \mathrm{mg} / \mathrm{dl}$, $9.4 \mathrm{mg} / \mathrm{dl}, 1.10 \mathrm{~g} / 100 \mathrm{~g} \mathrm{BW},-22.9 \%$, and 4 , respectively. The data for the mentioned parameter for the two animals survived in the group 10 (DS + CP + DS) were $628 \pm 34.5 \mathrm{mg} / \mathrm{dl}$, $7.6 \pm 0.3 \mathrm{mg} / \mathrm{dl}, 1.10 \pm 0.2 \mathrm{~g} / 100 \mathrm{~g} \mathrm{BW},-15.7 \pm 0.9 \%$, and 4 , respectively. These findings reveal the nonprotective role of $\mathrm{M}$ and DS hydration against CP-induced nephrotoxicity in female, while such observation was not seen in male.

3.3. The Effect of CP Alone on the Kidney. In order to determine the effect of CP alone, the data obtained in NS and CP groups (groups 6 and 7; male rats and groups 13 and 14; female rats) were compared statistically. The result is tabulated in Table 2, and the data revealed that CP increased significantly the serum levels of BUN, Cr, KW and KTDS which indicated kidney toxicity (Table 2).

3.4. The Effect of Hydration Protocols on CP-Induced Nephrotoxicity. In male rats, the serum levels of BUN and $\mathrm{Cr}$ and $\mathrm{ENa} \%$ were increased significantly $(P<0.05)$ in the $M+C P+M$ group, while these increased insignificantly in the DS + CP + DS group when compared with the CP-alone treated group. In addition, the $\mathrm{ClCr}$ also was decreased statistically in the $\mathrm{M}+\mathrm{CP}+\mathrm{M}$ group, as shown in Figure 1(a). The normalized KW and percentage change of $\mathrm{BW}$ in the $\mathrm{M}, \mathrm{NS}+\mathrm{CP}+\mathrm{CP}$ group have the lowest value compared with the $\mathrm{CP}$ alone treated group $(P<0.05)$. Also, a lower UF and a higher KTDS were detected insignificantly in $\mathrm{M}+\mathrm{CP}+\mathrm{M}$ groups, as shown in Figure 1(a).

In female rats, the serum levels of BUN and $\mathrm{Cr}$ and $\mathrm{ENa}$ $\%$ were increased significantly $(P<0.05)$ in $\mathrm{M}, \mathrm{NS}+\mathrm{CP}+\mathrm{NS}$ and NS $+\mathrm{CP}+\mathrm{NS}, \mathrm{F}$ groups when compared with the $\mathrm{CP}$ alone treated group, as shown in Figure 1(b). In addition, $\mathrm{ClCr}$ also decreased significantly in NS $+\mathrm{CP}+\mathrm{NS}, \mathrm{F}$ and $\mathrm{M}$, $\mathrm{NS}+\mathrm{CP}+\mathrm{NS}$ groups from the $\mathrm{CP}$ group $(P<0.05)$. The increase of KW and more $\mathrm{BW}$ lost were observed in the $\mathrm{NS}+\mathrm{CP}+\mathrm{NS}$ group from the CP group $(P<0.05)$, and a lower UF was collected significantly in NS $+\mathrm{CP}+\mathrm{NS}$ and $\mathrm{NS}+\mathrm{CP}+\mathrm{NS}, \mathrm{F}$ groups compared to the $\mathrm{CP}$ alone treated group $(P<0.05)$.

Finally, the serum and kidney levels of nitrite and MDA in both male and female rats treated with different hydration protocols are given in Table 3. The sample image of kidney tissue for each experimental group is shown in Figure 2.

\section{Discussion}

CP is used for a wide range of cancers during the chemotherapy process, but due of its side effect of nephrotoxicity, its use is limited. Proper hydration is proposed to reduce the $\mathrm{CP}$-induced nephrotoxicity. In this study, the effectiveness of five types of hydration methods was investigated. The findings indicated that hydration with mannitol or dextrose promote the mortality rate in female rats. The rats that received mannitol have the highest mortality rate. Only 1 female rat (16\%) and 3 male rats (50\%) survived at the end of the experiment. In addition, the mortality rate in the female dextrose-treated group (group 10) was 66\%.

$\mathrm{CP}$ filters via the glomerulus, and it excretes through the renal tubules [5]. $\mathrm{ClCr}$ is the best index to estimate the glomerular filtration rate (GFR), and the serum level of $\mathrm{Cr}$ has been increased when GFR has been attenuated $[16,20]$. These two parameters and others indexes such as serum levels of BUN and Cr, KW and KTDS altered in CP alone treated groups of male and female rats which verified the effect of CP. $\mathrm{CP}$ alone also decreased the kidney level of nitrite and increased the serum level of nitrite as other studies [21-23]. 

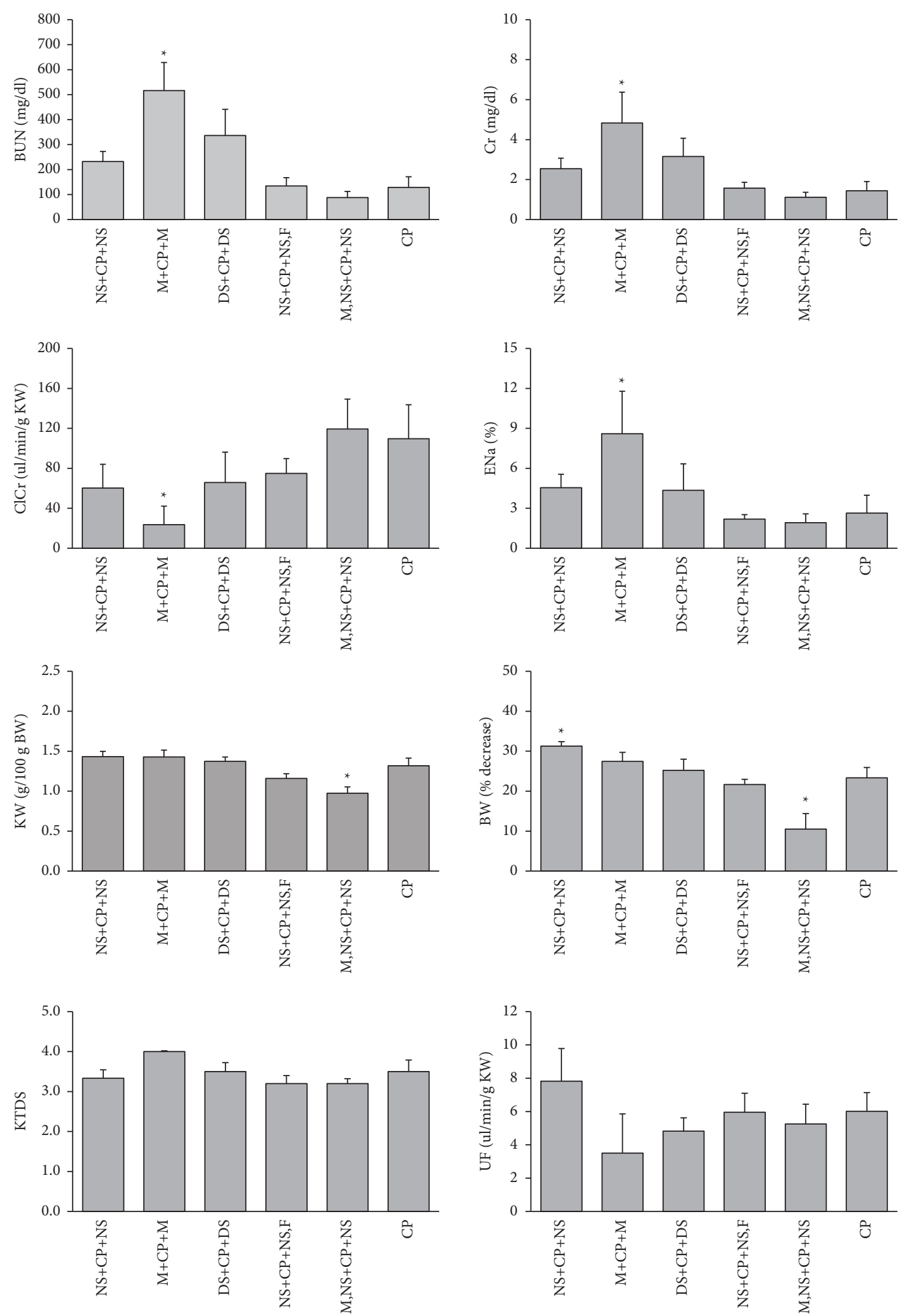

(a)

Figure 1: Continued. 

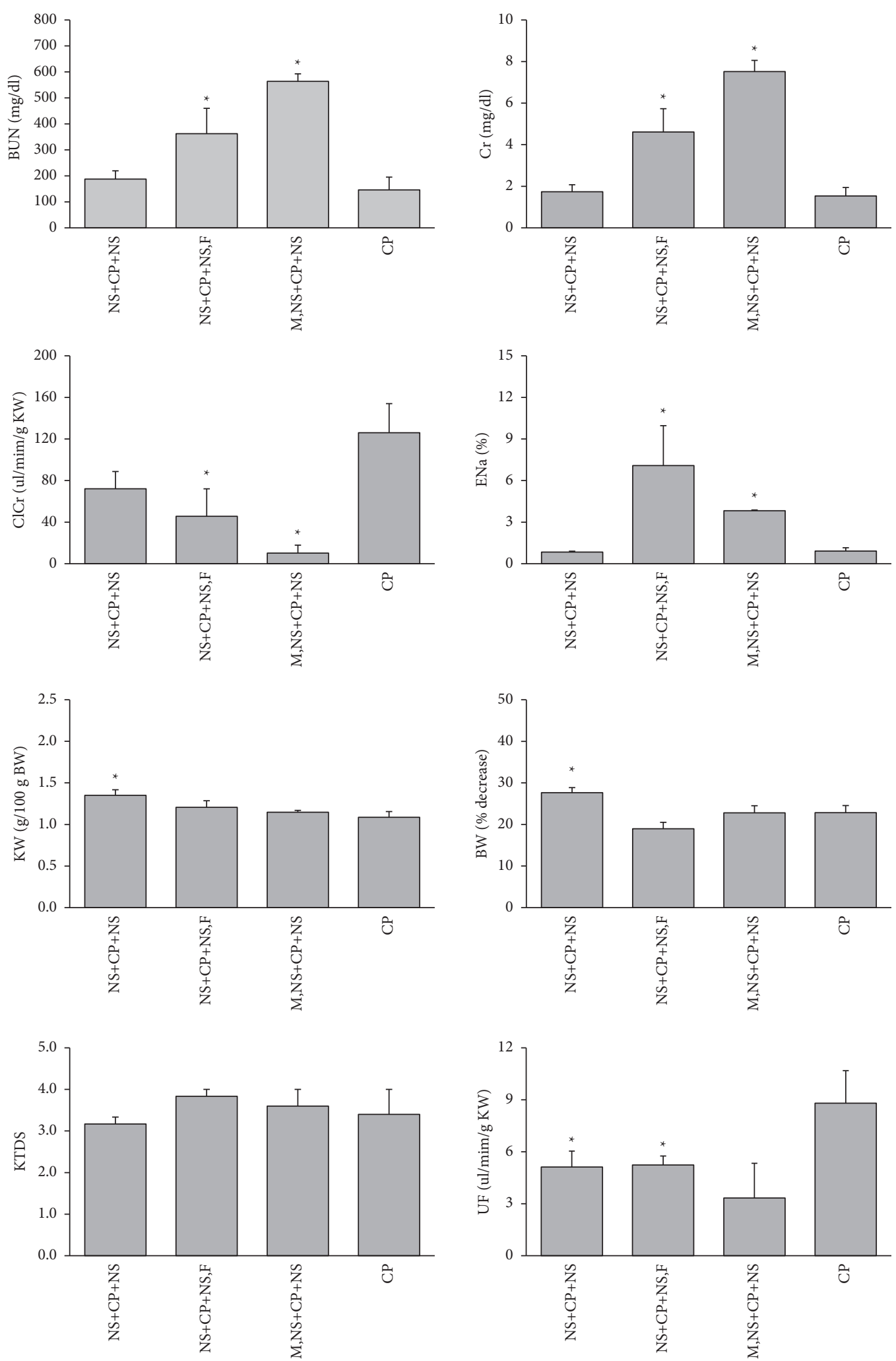

(b)

Figure 1: The serum levels of blood nitrogen urea (BUN) and creatinine (Cr), kidney weight (KW) per bodyweight (BW), percentage decrease of BW, kidney tissue damage score (KTDS), and urine flow rate (UF) among NS + CP + NS, M + CP + M (male), DS + CP + DS (male), NS + CP + NS, F, M, NS + CP + NS, and CP groups in male (a) and female (b) rats. *Significant difference from the CP group $(P<0.05)$ by the $t$-Student test. 
TABle 3: Serum and kidney levels of nitrite and MDA in both male and female rats treated with different hydration protocols.

\begin{tabular}{|c|c|c|c|c|c|c|c|c|}
\hline \multirow{2}{*}{$\begin{array}{l}\text { Group/ } \\
\text { parameter }\end{array}$} & \multicolumn{4}{|c|}{ Male } & \multicolumn{4}{|c|}{ Female } \\
\hline & $\begin{array}{l}\text { Snitrite } \\
(\mu \mathrm{mol} / \mathrm{l})\end{array}$ & $\begin{array}{c}\text { SMDA } \\
(\mu \mathrm{mol} / \mathrm{l})\end{array}$ & $\begin{array}{c}\text { Knitrite }(\mu \mathrm{mol} / \mathrm{g} \\
\text { tissue })\end{array}$ & $\begin{array}{c}\text { KMDA } \\
\text { (nmol/g tissue }\end{array}$ & $\begin{array}{l}\text { Snitrite } \\
(\mu \mathrm{mol} / \mathrm{l})\end{array}$ & $\begin{array}{l}\text { SMDA } \\
(\mu \mathrm{mol} / \mathrm{l})\end{array}$ & $\begin{array}{c}\text { Knitrite } \\
(\mu \mathrm{mol} / \mathrm{g} \text { tissue })\end{array}$ & $\begin{array}{c}\text { KMDA } \\
\text { (nmol/g tissue }\end{array}$ \\
\hline $\mathrm{NS}+\mathrm{CP}+\mathrm{NS}$ & $10.4 \pm 1.1$ & $3.1 \pm 0.2$ & $89.5 \pm 11.9^{*}$ & $21.7 \pm 4.5$ & $36.7 \pm 5.4$ & $1.1 \pm 0.2^{*}$ & $106.0 \pm 6.3$ & $26.7 \pm 3.0^{*}$ \\
\hline $\mathrm{M}+\mathrm{CP}+\mathrm{M}$ & $16.3 \pm 5.3$ & $2.2 \pm 0.2^{*}$ & $90.8 \pm \pm 15.7^{*}$ & $28.2 \pm 6.2$ & - & - & - & - \\
\hline $\mathrm{DS}+\mathrm{CP}+\mathrm{DS}$ & $22.1 \pm 6.5$ & $2.8 \pm 0.6$ & $122.2 \pm 8.1^{*}$ & $24.4 \pm 3.8$ & - & - & - & - \\
\hline $\mathrm{NS}+\mathrm{CP}+\mathrm{NS}, \mathrm{F}$ & $10.2 \pm 1.6$ & $2.6 \pm 0.4$ & $123.3 \pm 9.5^{*}$ & $38.3 \pm 2.2^{*}$ & $37.5 \pm 12.5$ & $2.5 \pm 0.4^{*}$ & $130.2 \pm 14.8$ & $41.1 \pm 9.9$ \\
\hline $\begin{array}{l}\mathrm{M}, \mathrm{NS}+\mathrm{CP}+ \\
\mathrm{NS}\end{array}$ & $14.5 \pm 3.5$ & $3.3 \pm 0.1$ & $152.1 \pm 4.8$ & $49.0 \pm 6.3^{*}$ & $36.4 \pm 21.2$ & $4.7 \pm 0.9$ & $109.9 \pm 7.9$ & $49.5 \pm 19.4$ \\
\hline $\mathrm{CP}$ & $13.4 \pm 3.6$ & $3.3 \pm 0.2$ & $148.0 \pm 9.1$ & $29.2 \pm 1.2$ & $24.6 \pm 3.8$ & $4.1 \pm 0.2$ & $103.7 \pm 7.0$ & $58.1 \pm 11.8$ \\
\hline
\end{tabular}

* Significant difference from CP $(P<0.05)$ obtained by the $t$-Student test.

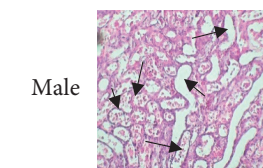

$\mathrm{NS}+\mathrm{CP}+\mathrm{NS}$

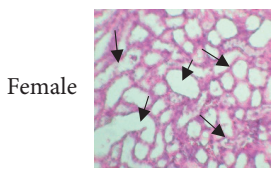

$\mathrm{NS}+\mathrm{CP}+\mathrm{NS}$

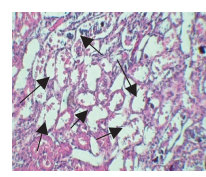

$\mathrm{M}+\mathrm{CP}+\mathrm{M}$

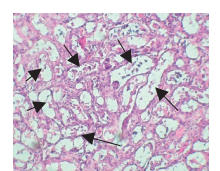

$\mathrm{M}+\mathrm{CP}+\mathrm{M}$

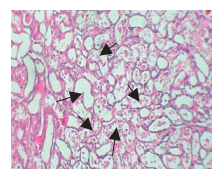

$\mathrm{DS}+\mathrm{CP}+\mathrm{DS}$

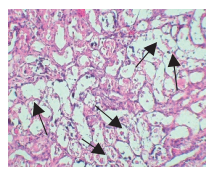

$\mathrm{DS}+\mathrm{CP}+\mathrm{DS}$

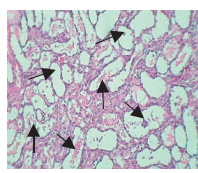

$\mathrm{NS}+\mathrm{CP}+\mathrm{NS}, \mathrm{F}$

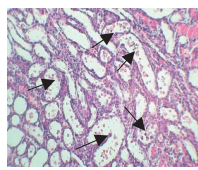

$\mathrm{NS}+\mathrm{CP}+\mathrm{NS}, \mathrm{F}$

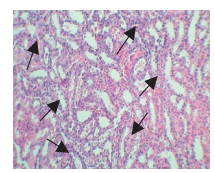

$\mathrm{M}, \mathrm{NS}+\mathrm{CP}+\mathrm{NS}$

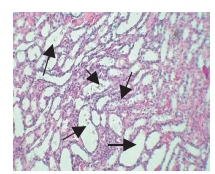

$\mathrm{M}, \mathrm{NS}+\mathrm{CP}+\mathrm{NS}$

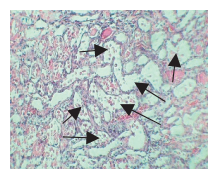

$\mathrm{CP}$

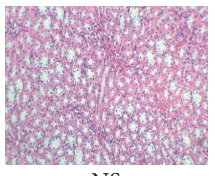

NS

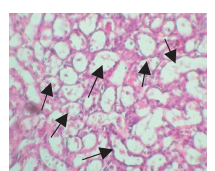

$\mathrm{CP}$

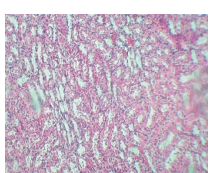

NS

Figure 2: The samples images $(\times 100)$ of kidney tissues in all experimental groups. The arrows indicate the tissue damage including vacuolization, dilatation, hyaline cast, debris, or degeneration.

Reviews of past studies illustrate controversial results about mannitol. Some of them reported that mannitol has a protective effect on the kidneys by its diuretic mechanism and reducing $\mathrm{CP}$ concentration $[24,25]$. On the contrary, some others studies declared no protective effect for mannitol, or even in confirmation with our study, they found mannitol to be significantly more nephrotoxic $[16,26,27]$. Morgan et al. indicated that forced diuresis increased the risk of acute kidney injury due to volume decreasing [27]. Shi et al. demonstrated that high dose of mannitol caused stress oxidative, destroyed cellular cytoskeleton, and promoted apoptosis [28]. Also, it has been indicated that mannitol causes osmotic nephrosis and lead to acute renal failure $[29,30]$. Some studies also have shown the benefits of mannitol on lowering the CP-induced nephrotoxicity $[16,27]$. However, the subsequent study has not reported a significant difference between hydration plus or without mannitol [31,32]. There also is concern about the use of mannitol due to vasoconstriction feature and the possibility of prerenal azotemia [33, 34].

The nephroprotective effect of mannitol and furosemide have also been compared. Santoso et al. concluded that furosemide-saline has more nephroprotective effect compared with mannitol [16], while other studies considered no significant difference in their protective role [26]. However, in our study, no significant protective effect was observed for furosemide-saline hydration in male rats, but the serum levels of BUN and Cr increased significantly when compared with the CP group in female rats. The protective effect of furosemide like mannitol is still debatable [16], while the neutral effect and adverse effect of furosemide on the kidney also are reported [35-37].

An increase in the glucose level to perform a suitable diuresis is another issue for challenging. Diabetes has been considered as one of the risk factors for various cancers such as colon, chest, pancreas, and liver, but it plays a protective role in reducing the toxic effects of $\mathrm{CP}$. Intensity and duration of diabetes mellitus have a direct relationship with the severity of kidney toxicity, and the protective effects are also reduced by controlling diabetes [38]. Therefore, the protective effects of dextrose saline (normal saline with glucose) with the likelihood of a similar role of diabetes also need to be considered.

Finally, in the current study, we reported the data for male and female rats separately, and some differences were seen without any analysis. However, it is well documented that CP-induced nephrotoxicity is gender related [6]. Pezeshki et al. mentioned that administration of estrogen increases severity of CP-induced nephrotoxicity [39], so the increase in the serum level of BUN and $\mathrm{Cr}$ and other factors in some female groups may be due to estrogen hormone. Generally, it seems that gender is an important factor affecting the hydration process during CP therapy.

\section{Conclusion}

Although mannitol and dextrose in clinical protocols for the reduction of CP-induced nephrotoxicity may be suggested, however, this study not only shows that these two hydration protocols do not protect the kidney but also they are harmful 
and the use of these substances need to be reconsidered seriously in male and female genders. It seems that hydration with saline alone is more safe than other protocols investigated in this study.

\section{Data Availability}

The data used to support the findings of this study are available from the corresponding author upon request.

\section{Conflicts of Interest}

The authors declare that they have no conflicts of interest.

\section{Authors' Contributions}

Mohammad-Sedigh Khosravi and Alireza Samimiat contributed equally to this work.

\section{Acknowledgments}

This research was supported by Isfahan University of Medical Sciences (399350 and 399369).

\section{References}

[1] R. P. Miller, R. K. Tadagavadi, G. Ramesh, and W. B. Reeves, "Mechanisms of cisplatin nephrotoxicity," Toxins, vol. 2, no. 11, pp. 2490-2518, 2010.

[2] S. Manohar and N. Leung, "Cisplatin nephrotoxicity: a review of the literature," Journal of Nephrology, vol. 31, no. 1, pp. 15-25, 2018.

[3] J. r. T. Hartmann, C. Kollmannsberger, L. Kanz, and C. Bokemeyer, "Platinum organ toxicity and possible prevention in patients with testicular cancer," International Journal of Cancer, vol. 83, no. 6, pp. 866-869, 1999.

[4] N. Pabla and Z. Dong, "Cisplatin nephrotoxicity: mechanisms and renoprotective strategies," Kidney International, vol. 73, no. 9, pp. 994-1007, 2008.

[5] X. Yao, K. Panichpisal, N. Kurtzman, and K. Nugent, "Cisplatin nephrotoxicity: a review," The American Journal of the Medical Sciences, vol. 334, no. 2, pp. 115-124, 2007.

[6] M. Nematbakhsh, S. Ebrahimian, M. Tooyserkani, F. Eshraghi-Jazi, A. Talebi, and F. Ashrafi, "Gender difference in Cisplatin-induced nephrotoxicity in a rat model: greater intensity of damage in male than female," Nephro-Urology Monthly, vol. 5, no. 3, pp. 818-21, 2013.

[7] Y.-Z. Li, S. Ren, X.-T. Yan et al., "Improvement of Cisplatininduced renal dysfunction by Schisandra chinensis stems via anti-inflammation and anti-apoptosis effects," Journal of Ethnopharmacology, vol. 217, pp. 228-237, 2018.

[8] H. Yang, W. Li, L. Wang et al., "The protective effects of sika deer antler protein on cisplatin-induced nephrotoxicity," Cellular Physiology and Biochemistry, vol. 43, no. 1, pp. 395-404, 2017.

[9] M. Nematbakhsh, Z. Pezeshki, F. E. Jazi et al., "Cisplatininduced nephrotoxicity; protective supplements and gender differences," Asian Pacific Journal of Cancer Prevention: APJCP.vol. 18, no. 2, pp. 295-314, 2017.

[10] A. Ibrahim, F. A. Al-Hizab, A. I. Abushouk, and M. M. AbdelDaim, "Nephroprotective effects of benzyl isothiocyanate and resveratrol against cisplatin-induced oxidative stress and inflammation," Frontiers in Pharmacology, vol. 21, no. 9, Article ID 1268, 2018.

[11] S. A. Abdellatief, A. A. A. Galal, S. M. Farouk, and M. M. Abdel-Daim, "Ameliorative effect of parsley oil on cisplatin-induced hepato-cardiotoxicity: a biochemical, histopathological, and immunohistochemical study," Biomedicine \& Pharmacotherapy, vol. 86, pp. 482-491, 2017.

[12] M. El Hamamsy, N. Kamal, N. S. Bazan, and M. El Haddad, "Evaluation of the effect of acetazolamide versus mannitol on cisplatin-induced nephrotoxicity, a pilot study," International Journal of Clinical Pharmacy, vol. 40, no. 6, pp. 1539-1547, 2018.

[13] I. H. Kim, M. J. Kwon, J. H. Jung, and T. J. Nam, "Protein extracted from Porphyra yezoensis prevents cisplatin-induced nephrotoxicity by downregulating the MAPK and NF- $\kappa \mathrm{B}$ pathways," International Journal of Molecular Medicine, vol. 41, no. 1, pp. 511-520, 2018.

[14] Y.-N. Yu, H. Chen, and Y. Li, "Protect effect of bicyclol on cisplatin-induced nephrotoxicity in mice," Archives of Toxicology, vol. 83, no. 4, pp. 381-387, 2009.

[15] F. Ashrafi, Z. Ebrahimi, and M. Nematbakhsh, "Effect of short hydration on cisplatin-induced nephrotoxicity in cancer patients: a retrospective study," International Journal of Hematology-Oncology and Stem Cell Research, vol. 11, no. 4, pp. 262-267, 2017.

[16] J. T. Santoso, J. A. Lucci, R. L. Coleman, I. Schafer, and E. V. Hannigan, "Saline, mannitol, and furosemide hydration in acute cisplatin nephrotoxicity: a randomized trial," Cancer Chemotherapy and Pharmacology, vol. 52, no. 1, pp. 13-18, 2003.

[17] M. Nematbakhsh, F. Ashrafi, H. Nasri et al., “A model for prediction of cisplatin induced nephrotoxicity by kidney weight in experimental rats," Journal of Research in Medical Sciences: The Official Journal of Isfahan University of Medical Sciences, vol. 18, no. 5, pp. 370-373, 2013.

[18] M. Nematbakhsh, F. Ashrafi, Z. Pezeshki et al., "A histopathological study of nephrotoxicity, hepatoxicity or testicular toxicity: which one is the first observation as side effect of Cisplatin-induced toxicity in animal model?" Journal of Nephropathology, vol. 1, no. 3, pp. 190-193, 2012.

[19] N. S. Bryan and M. B. Grisham, "Methods to detect nitric oxide and its metabolites in biological samples," Free Radical Biology and Medicine, vol. 43, no. 5, pp. 645-657, 2007.

[20] A. S. Levey, R. D. Perrone, and N. E. Madias, "Serum creatinine and renal function," Annual Review of Medicine, vol. 39, no. 1, pp. 465-490, 1988.

[21] R. Eguchi, Y. Fujimori, T. Ohta, K. Kunimasa, and T. Nakano, "Calpain is involved in cisplatin-induced endothelial injury in an in vitro three-dimensional blood vessel model," International Journal of Oncology, vol. 37, no. 5, pp. 1289-1296, 2010.

[22] S. Y. Saad, T. A. O. Najjar, M. H. Daba, and A. C. Al-Rikabi, "Inhibition of nitric oxide synthase aggravates cisplatin-induced nephrotoxicity: effect of 2-amino-4-methylpyridine," Chemotherapy, vol. 48, no. 6, pp. 309-315, 2002.

[23] M. Ekor, G. O. Emerole, and E. O. Farombi, "Phenolic extract of soybean (Glycine max) attenuates cisplatin-induced nephrotoxicity in rats," Food and Chemical Toxicology, vol. 48, no. 4, pp. 1005-1012, 2010.

[24] D. J. Crona, A. Faso, T. F. Nishijima, K. A. McGraw, M. D. Galsky, and M. I. Milowsky, "A systematic review of strategies to prevent cisplatin-induced nephrotoxicity," The Oncologist, vol. 22, no. 5, pp. 609-619, 2017.

[25] K. Muraki, R. Koyama, Y. Honma et al., "Hydration with magnesium and mannitol without furosemide prevents the 
nephrotoxicity induced by cisplatin and pemetrexed in patients with advanced non-small cell lung cancer," Journal of Thoracic Disease, vol. 4, no. 6, pp. 562-8, 2012.

[26] G. Makimoto, K. Hotta, I. Oze et al., "Randomized study comparing mannitol with furosemide for the prevention of cisplatin-induced renal toxicity in non-small cell lung cancer: the OLCSG1406 trial," Asia-Pacific Journal of Clinical Oncology, vol. 17, no. 1, pp. 101-108, 2020.

[27] K. P. Morgan, L. W. Buie, and S. W. Savage, "The role of mannitol as a nephroprotectant in patients receiving cisplatin therapy," The Annals of Pharmacotherapy, vol. 46, no. 2, pp. 276-281, 2012.

[28] J. Shi, J. Qian, H. Li, H. Luo, W. Luo, and Z. Lin, "Renal tubular epithelial cells injury induced by mannitol and its potential mechanism," Renal Failure, vol. 40, no. 1, pp. 85-91, 2018.

[29] P. Goldwasser and S. Fotino, "Acute renal failure following massive mannitol infusion. Appropriate response of tubuloglomerular feedback?" Archives of Internal Medicine, vol. 144, no. 11, pp. 2214-2216, 1984.

[30] H. R. Dorman, J. H. Sondheimer, and P. Cadnapaphornchai, "Mannitol-induced acute renal failure," Medicine, vol. 69, no. 3, pp. 153-159, 1990.

[31] L. Leu and D. Baribeault, "A comparison of the rates of cisplatin (CDDP) - induced nephrotoxicity associated with sodium loading or sodium loading with forced diuresis as a preventative measure," Journal of Oncology Pharmacy Practice, vol. 16, no. 3, pp. 167-171, 2010.

[32] A. Ruggiero, D. Rizzo, G. Trombatore, P. Maurizi, and R. Riccardi, "The ability of mannitol to decrease cisplatininduced nephrotoxicity in children: real or not?" Cancer Chemotherapy and Pharmacology, vol. 77, no. 1, pp. 19-26, 2016.

[33] P. Dhillon, E. Amir, M. Lo et al., "A case-control study analyzing mannitol dosing for prevention of cisplatin-induced acute nephrotoxicity," Journal of Oncology Pharmacy Practice, vol. 25, no. 4, pp. 875-883, 2019.

[34] K. Doi, N. Ogawa, E. Suzuki, E. Noiri, and T. Fujita, "Mannitol-induced acute renal failure," The American Journal of Medicine, vol. 115, no. 7, pp. 593-594, 2003.

[35] M. Gehr, S. Chopra, J. Kaufman, D. Chase, and W. Flamenbaum, "The effect of furosemide (F) ON CISdiamminedi-chloroplatinum (CP) induced acute-renal-failure (arf)," Kidney International, Blackwell Science INC 350 MAIN ST, Malden, MA, USA, 1981.

[36] D. Lehane, A. Winston, R. Gray, and Y. Daskal, "The effect of diuretic pre-treatment on clinical, morphological and ultrastructural cis-platinum induced nephrotoxicity," International Journal of Radiation Oncology, Biology, Physics, vol. 5, no. 8, pp. 1393-1399, 1979.

[37] C. M. Mach, C. Kha, D. Nguyen et al., "A retrospective evaluation of furosemide and mannitol for prevention of cisplatin-induced nephrotoxicity," Journal of Clinical Pharmacy and Therapeutics, vol. 42, no. 3, pp. 286-291, 2017.

[38] M. C. da Silva Faria, N. A. G. d. Santos, M. A. Carvalho Rodrigues, J. L. Rodrigues, F. Barbosa Junior, and A. C. d. Santos, "Effect of diabetes on biodistribution, nephrotoxicity and antitumor activity of cisplatin in mice," Chemico-Biological Interactions, vol. 229, pp. 119-131, 2015.

[39] Z. Pezeshki, M. Nematbakhsh, H. Nasri et al., "Evidence against protective role of sex hormone estrogen in Cisplatininduced nephrotoxicity in ovarectomized rat model," Toxicology International, vol. 20, no. 1, pp. 43-7, 2013. 